\title{
SOCIAL WORK, ETHICS AND VULNERABLE GROUPS IN THE TIME OF CORONAVIRUS AND COVID-19
}

\author{
KATHLEEN J. FARKAS ${ }^{1} \&$ J. RICHARD ROMANIUK ${ }^{2}$ \\ ${ }^{1}$ Case Western Reserve University, Jack, Joseph and Morton Mandel School of Applied Social Sciences, \\ 11235 Bellflower Road, Cleveland, Ohio 44109, USA. ORCID: 0000-0002-1937-3603, Email: kjf@case. \\ edu \\ ${ }^{2}$ Case Western Reserve University, Jack, Joseph and Morton Mandel School of Applied Social Sciences, \\ 11235 Bellflower Road, Cleveland, Ohio 44109, USA. ORCID: 0000-0002-8568-6587, Email: irr3@case. \\ edu
}

ABSTRACT: The profession of social work is dedicated to the betterment of society and to the protection of marginalized and vulnerable groups. The profession's mission is detailed in the set of seven core values: service; social justice; dignity and work of the person; importance of human relationships; integrity; and competence. Relationships between people and among groups are the primary tools of social work assessment, intervention and evaluation. In the time of coronavirus and COVID-19, there are many challenges for professional practitioners to adhere to social work's core values as well as to maintain their own health and welfare in a time of uncertain and rapidly changing situations. This paper will examine the challenges and innovations for each social work core value and present ideas for innovation and adaptation suited to these times. The paper will present challenges and innovations using examples of two community agencies providing services to people who are homeless and addicted. In summary we will offer some insights and expectations for the future of social work in the coming years, after this experience of coronavirus and COVID-19. KEYWORDS: homeless, addiction, pandemic, social work, COVID-19 


\section{INTRODUCTION}

For the profession of social work to adequately respond to the present pandemic, we need to learn from the past. Although the 1918 influenza and COVID-19 are two distinct viruses causing different disorders, the dimensions of the two pandemics and the emerging human needs are similar. Just over one hundred years ago, the influenza pandemic of 1918 presented severe health, financial and social challenges (Ott, Shaw, Danila \& Lynfield 2007). US social workers responded to the pandemic having been already mobilized by the human needs associated with WWI. Hospital based social workers were on the front lines of care and developed a strong professional identity that carried on well after the pandemic subsided (Kerson 1979). Rosoff (2008) well in advance of the current pandemic, outlined the ethical duties and challenges for social work professionals. Social work has continued as a profession founded on the ideal of making the world a better place for all people. The two founding approaches, charity organization societies and the settlement house movement laid the groundwork for today's focus on both the person and the environment. In times of crisis, the profession has attended to the needs of developing community structures and organizational resources as well as responding to the personal needs of individuals, families and groups. Maglajlic (2019), for example, reviews social work research in response to several types of natural disasters and more recently, Beddoe (2020) writes on the professions reactions to the devastating Australian fires. Throughout its history, the profession has been guided by its focus on vulnerable groups and by values and ethical principles that shape responses for individuals, families, and groups as well as for organizations and communities.

\section{VULNERABILITY IN A PANDEMIC}

In the case of the COVID-19 pandemic, the level of vulnerability is similar to that described for the1918 influenza pandemic, as both are the result of a novel virus and the consequent viral infection affecting the respiratory system; all humans are vulnerable. In a pandemic, vulnerability can be functionally defined for those individuals in relation to their susceptibility to infection and their ability to overcome illness (Hutchins et al. 2009a; Smith 2020). More vulnerable individuals are those who are the most exposed to infection; for example, those who live in densely populated areas or in institutions or those who commute using crowded busses or subways. Others are vulnerable due to their weaker or compromised immune system - elderly people and those with chronic health conditions including heart disease, asthma or diabetes. Those with limited access to health care, quality nutrition and supportive resources may also be counted among vulnerable individuals in a pandemic. Race may well prove to be a significant variable in determining vulnerability to Coronavirus and COVID19, given racial discrimination its effects on access to services in the U S (Hutchins et al. $2009 \mathrm{~b})$. Also among the vulnerable are those who do not speak or understand English well since they may neither be able to understand public health advisories or communicate their own health needs and concerns. People with physical disabilities are at risk if they have to move from their specially adapted living situations or if they 
are isolated from their usual support systems of care. Yet others are vulnerable not only because of the infectious agent, but also because the recommendations for social quarantine and social distancing put them at risk for the negative consequences of loneliness, isolation or domestic violence. This brief review of examples of functional vulnerability illustrates that a significant part of our society consists of individuals with differing and special needs during a pandemic.

One may assume the American public is aware, in this time of crisis, that vulnerable individuals need special protections. However, not only individuals, but also groups including $\mathrm{LGBT}^{+}$and people of Chinese heritage bear a special vulnerability based on group status and must depend on special protection against discrimination and oppression. As President Donald Trump continued to refer to the novel Coronavirus as the "Chinese virus" in direct opposition to World Health Organizations guidelines (World Health Organization 2015), incidents of racially motivated harassment and abuse increased fueled by prejudice and fear (Cabanatuan 2020). In response to growing xenophobia and discrimination towards Asian people, U.S. House Representative Grace Meng introduced a resolution to denounce anti-Asian sentiment caused by coronavirus (Meng 2020).

Recent legal changes that allow certain social services to discriminate against LGBT+ put members of that group in danger during a pandemic. In recent weeks, advocacy organizations sued the U.S. Department of Health and Human Services regarding the announcement that it would stop enforcing anti-discrimination protections against federal grantees that deny services to, or otherwise discriminate against, individuals. Lambda Legal, an organization protecting LGBT+ rights, presented the following situations to illustrate the increased vulnerability of LGBT+ during a pandemic (Nemir 2020):

- Students experiencing homelessness are susceptible to discrimination as they seek shelter through HHS' Runaway and Homeless Program, at a time when colleges and universities have shut down housing to help halt the spread of COVID-19.

- Federally funded foster care agencies can refuse to place children with families because of a prospective host family's sexual orientation or gender identity, limiting the pool of potential homes for kids who need them.

- Child welfare agencies and homelessness service providers can engage in abusive and discriminatory practices, including verbal and physical abuse, conversion therapy, and forcing LGBTQ youth to accept services that deny their sexual orientation or gender identity.

- A federally funded adult daycare provider could put a sign on the door saying, "No Trans People May Enter."

- Entities administering falls prevention grants could choose to serve only straight people at risk of falling. 
- LGBTQ older adults are now vulnerable to providers that subject them to harassment or refuse to offer services, such as home delivered meals, on the basis of their sexual orientation or gender identity, at a time when senior centers are shutting down in major metropolitan centers to help combat the spread of COVID-19.

Two conclusions can be drawn from these examples: first, any discrimination allowed during a time of peace may become a matter of life and death in a period of crisis; and, secondly, non-profit advocacy groups are essential to give voice to vulnerable groups who otherwise cannot defend themselves.

\section{ETHICAL MANDATES FOR SOCIAL WORKERS DURING A PANDEMIC}

The National Association of Social Workers (NASW 2020) has codified professional values, principles and standards. Most recently, in response to the Coronavirus (Covide-19) pandemic, the NASW president referenced the code as well as social work's dual focus on people and community:

As social workers who adhere to the NASW Code of Ethics, we need to be aware of our obligation to ,provide appropriate professional services in public emergencies to the greatest extent possible' (6.04). In doing so, we can advocate for needed resources and policies related to supporting members of our communities and the people we serve who may be at risk due to accessibility of food, medical care, medication and emotional support during this time. (https://www. socialworkers.org/About/Ethics)

Each of these core values and principles can be applied to social work's ethical duties and dilemmas in response to the pandemic of Coronavirus and COVID19. After a brief discussion of the values and ethical principles, we will illustrate their application by two social services agencies helping two specific subpopulations of vulnerable people: those who struggle with addiction and those who are homeless.

Value of Service: Social workers' primary goal is to help people in need and to address social problems

The core value of service sets the direction of any professional work with clients. This value makes the needs and wellbeing of the client paramount. Each phase of the social work process- engagement; assessment; intervention; evaluation; and termination- is carried out with the needs of the client at the forefront. The Coronavirus (COVID-19) does not necessarily change this focus on service to the client. Social workers are called to continue their work to serve in the many settings in which they practice. Like other health care professionals, social workers continue to be in relationship with clients and to provide needed resources and services. Clients with access to computers and telephones maintain social work services using on-line support groups and telehealth counseling options (Murray 2020) and twelve step support groups (Partnership 
for Drug-Free Kids 2020). On-line education providers are opening classes on the skills in tele-health to increase the numbers of skilled professionals delivering on-line and telephone services. As social distancing practices grow, more and more organizations, including the National Alliance on Mental Illness (NAMI) and 12 Step Programs, offer individual and group services through tele-health platforms. The fact that people with lower incomes do not have ready access to computers and internet access limits the number of clients who can be served by telehealth efforts. Concerns about confidentiality and privacy also limit some clients' openness to using tele-health options for information and support.

Unlike institutional or office-based health care professions, many social workers practice in the community and work face-to-face with society's most vulnerable. These social work professionals use a community/home visit strategy to maintain contact with clients. The value of service, in these situations, may well create a tension between professional and personal values, for all of us are vulnerable to the virus and must avoid situations that spread infection. To complicate the situation, many US governors issued orders to "shelter in place" so to "flatten the curve" (Bunis \& Rough 2020). This public health restriction closed community spots social workers routinely used as their offices in the community. Libraries, fast food restaurants, public buildings are all closed, leaving very few places for client meetings. Some community social workers have decided to meet with clients in their cars, a very enclosed space which might hasten spread of the virus (Farkas 2020). Social workers in institutions such hospitals, nursing homes, residential care and shelters for homeless persons face particular risks of interacting with at-risk people in closed settings - like other medical professionals, but without protective clothing or masks. While the core value of service is upheld, it should not come with increased personal risk of contagion for the social work professional, but the facts of Coronavirus and COVID-19 have created a competing set of demands to serve their clients or to protect themselves and their families from infection. How these issues are addressed is presented in two examples at the end of this text.

\section{Value of Social Justice: Social workers challenge social injustice}

The core value of social justice is associated with the skills and tasks of advocacy and policy reform. Social workers are bound to speak out about inequities and injustices they see and experience in the world. The Coronavirus and COVID19 pandemic has shed new light on a number of social justice and advocacy issues of importance to social work professionals. The "digital divide" limits access to on-line counseling, support groups and other services to those who can afford personal computers and internet at home. For high risk populations, especially those with fewer social connections, the lack of personal computers and internet reduces access for news, social connections, medical care and food during virus containment periods. Hence, the pandemic has sharpened this digital divide into a social justice issue and accentuates the need for enhanced advocacy efforts. Mandated work stoppages in many states have led to job loss, income shortages and financial hardships. Gaps in health insurance 
coverage and the loss of insurance linked to employment status will require renewed advocacy efforts in the post-pandemic era. It can be expected that some in the social work profession may find themselves out of work and the recipients of benefits they previously assisted clients in obtaining.

Value of Dignity and Worth of the Person: Social workers respect the inherent dignity and worth of the person

Social workers, from the beginning of their training, are steeped in the importance of each individual's unique dignity and worth. Even in the most trying times, social workers focus on the needs of the client and advocate for their welfare and wellbeing. The burdens on the health care system to care for seriously ill persons have led to ideas of rationing and Italy's horrific experience of having to decide who will die and who will live because there isn't adequate treatment for all. In the US, these dire conditions have not yet arisen, but discussions of 'rationing' require careful thought and ethical practices. Dan Patrick, the lieutenant governor of Texas suggested that older people, grandparents, in particular, would be willing to die of the virus to save the economy for their grandchildren (Murphy 2020). In a March 22, 2020 New York Times opinion column, Aronson argues, that the implicit criterion for allowing people to die from COVID19 is age; she questions why is it okay to allow older people to die and why society accepts age the key criterion for these life and death decisions. The very idea of rationing of life-saving health care resources is counter to social work values, but in many places, this may be the reality during such a pandemic and spread of serious illness. Under these pressures, social workers, and the rest of society, will find themselves facing heart-breaking ethical dilemmas - with no clear guidance, but with the ethical mandate to uphold the dignity and work of all people, especially the most vulnerable.

The Coronavirus and the resulting illness, COVID19, was first detected in Wuhan, China and spread throughout Asia prior to widespread infections in Western Europe and in the United States. Despite the efforts of the World Health Organization to de-couple disease and geography (World Health Organization 2015) the Coronavirus (COVID19) has been called the 'Asian Virus' raising and strengthening anti-Asian stereotypes and stigma. As previously mentioned, reports of verbal and physical violence towards Asian people have been reported in various media outlets. Social workers are bound by the social justice value to counter these stereotypes and to speak up on behalf of those who are victimized by hatred and ignorance. In these times, social workers must set personal and public examples and be straightforward about the use of the correct terminology (COVID19) and to advocate for any who are stigmatized or abused because of national origin.

Value of Importance of Human Relationships: Social workers recognize the central importance of human relationships

Social workers practice across many settings and with many different types of popula- 
tions and social problems. However, the relationship with client is the central method of work. As a way to mitigate the infection rate and to prevent serious illness, public health advisories have included the practices of social distancing, self-quarantine and self- isolation. In times when personal contact is limited by public health practices, social workers must be innovative to maintain their work with clients and find ways to balance personal health with client services. Social workers are turning to on-line options, social distancing in open settings, phone contacts and written communication to stay connected with their clients, knowing the importance of human relationships for wellbeing, especially in times of crisis.

Social workers also have families and many are caregivers for young children and/ or for older adults. They have personal as well as professional duties to uphold, so the duty to service is not without some tension for social workers trying to balance personal health and safety with their professional duties to serve. Social workers on the front lines of service, with deep ties to their clients, find that social relationships are hampered by closings of public places, inability to contact clients, cancellations of programs and the lack of computers and internet access - creating ethical tension with no clear means of resolution.

Value of Integrity: Social workers behave in a trustworthy manner and the Value of Competence: Social workers practice within their areas of competence and develop and enhance their professional expertise.

These final two values and ethical principles are linked in this time of Coronavirus (COVID19). Behaving in a trustworthy manner includes setting a healthy example for clients by following public health advice, washing hands before and after any client contact, practicing social distancing and sharing facts about the pandemic that are grounded in science. While the profession upholds evidence-based practices and empirically supported knowledge, few social work practitioners are conversant in virology or public health models of containment. In this time, social workers have an ethical duty to stay up to date with science-based advice on how to behave during the pandemic and to be able to communicate this knowledge accurately with our clients and our friends and families.

\section{ADDRESSING VULNERABILITY AMONG PEOPLE WHO ARE HOMELESS AND ADDICTED TO SUBSTANCES}

\section{Methodology}

To focus on the social work profession's response to the pandemic, the authors used the following methodology. The authors searched on-line databases to access scholarly literature using keywords of 'pandemic, social work, ethics, and values'. The authors also used online databases to access local and national news sources covering the spread of the virus and COVID19 throughout the United States. The focus for news articles was on the three most affected cities during the last two weeks of March 2020, but news stories from other localities were used to illustrate specific virus-related issues and concerns. Phone interviews were conducted with administrative staff from the two largest Cleveland-based agencies providing services to people who are home- 
less and those who deal with addiction. One administrator from each site was interviewed. The agency's web-based materials were also reviewed for background and descriptive information about each agency.

Those who are homeless and those addicted to substances present two vulnerable groups during the COVID19 pandemic. Individuals with one or both of these problems experience ongoing crises, in compromised health and often in less than ideal living conditions. The primary public health response has been to 'stay home', in order to 'flatten the curve'. However, this requirement presents a significant, even seemingly insurmountable, problem for those with no access to safe housing. The homeless are the best example of people who cannot respond on their own to this request (Schuetz 2020). In 2019 there were 560,000 homeless in the United States, according to a recent report of the United States Department of Housing and Urban Development. The homeless are usually living in conditions of poor hygiene in environments exposing them to infections. They may have ongoing health problems magnified by poor nutrition and a lack of health care. Homelessness is of concern at any time, but this social problem takes on special urgency to stop the spread of the highly contagious Coronavirus. The next section reviews the steps taken by three large US cities to 'flatten the curve' of infection among the homeless population.

In 2019, 1,000 people died on the streets in Los Angeles (The Times Editorial Board 2020). To help their 59,000 homeless in this time of COVID19, the city of Los Angeles prepared hundreds of hand-washing stations, mobile showers, and portable toilets near places where the homeless gather. The city and county are leasing hotel and motel rooms for those who need housing. Forty-two city recreation centers are being converted to shelters with 6,000 beds. City authorities agreed to keep all cots in the facilities six feet apart, so additional space is needed. Social workers have joined with other health and human service professionals to carry out these efforts.

In New York City (Ricciulli 2020) authorities emphasized education on how people can avoid coronavirus infection. Information about the specifics of the COVID-19 pandemic is given in different languages to be accessible to all who live in the city. City authorities cancelled all meetings and gatherings in shelters and helped to improve the sanitary conditions of the homeless. Outreach workers at first were asked not to offer help to the homeless on the streets because this could enable the homeless to resist seeking help in shelters. However, after advocacy work of nonprofit organizations, this policy was reversed, and outreach workers started educating the homeless about how to protect themselves from infection and to screen them for the signs of respiratory symptoms. 550 outreach workers have been trained for those services. Christine Quinn, the CEO of shelter Win, said that they keep the appropriate distance between cots, according to CDC guidelines, but also try to keep a sense of connection - “because homeless people feel every single day like they are 'other'. [We] don't want that to escalate; that type of escalation, particularly for people dealing with addiction issues, is very life-threatening" (Ricciulli 2020).

In Seattle, one of the first 'hotspots' for the US pandemic, (Monnier 2020) there are 12,000 homeless. Seattle authorities also highlighted education to protect the public 
from infection and to help the homeless find health and housing resources. Responses to the crisis include improving the hygiene situation in shelters and seeking more shelter space to accommodate hundreds more people.

This pandemic is at the beginning in the US, so one can assume there will be more innovations and policy changes in how large cities address the needs. To understand the ways in which social service agencies have seen the problems and mobilized their resources, we contacted two Cleveland based agencies, Stella Maris and Lutheran Metropolitan Ministry Men's Shelter, to learn about the Cleveland community and the local social work responses These two agencies are well known in their dedication of helping the most vulnerable populations and have begun efforts to address the needs of their homeless clients as the Coronavirus pandemic spreads to the Midwest.

\section{Background Description of Stella Maris}

Located on Cleveland's Near-West Side and serving the Greater Cleveland community for over 72 years, Stella Maris offers a comprehensive continuum of care and is one of only three accredited subacute detoxification programs in Cuyahoga County. The mission of Stella Maris is to provide quality chemical dependency treatment and mental health services to our community, regardless of race, sex, gender identification, religion or ability to pay. The majority of clients are at or below the federal poverty level, without medical insurance, and often homeless. In support of this mission, Stella Maris is committed to providing detoxification, outpatient services, and supportive housing to a population of homeless, impoverished, and uninsured individuals in their quest for sobriety and self-sufficiency. Stella Maris is known for its compassionate services, exemplary partnerships, and strong outcomes. With the current opioid epidemic, 91\% of Stella Maris' clients are treated for addiction to opioids, or opioids in combination with other drugs. Stella Maris operates Joint Commission Accredited programs that includes Medically-Supervised Detoxification from alcohol and/or from other drugs for men and women, as well a Partial Hospitalization Program (PHP) which serves as a bridge between detoxification and intensive outpatient treatment. The PHP program keeps clients who are suffering from post-acute withdrawal engaged in treatment while also offering clinically intensive programming. The Intensive Outpatient Program (IOP) provides intensive group counseling, individual counseling, case management, and relapse prevention. Stella Maris also offers a Non-Intensive Outpatient Program focused on relapse prevention and case management to support those who have completed treatment. Additionally, Stella Maris provides on-campus Ohio Recovery Housing for men in a 46-bed facility that offers chemical dependency education, case management, psychiatric and medical care, and vocational counseling within a therapeutic community. Stella Maris also has two off-campus Ohio Recovery Housing houses: Carlyle, a 10-bed male-only recovery house, and Walton, a female-only, 17-bed recovery house. Recovery housing provides an alcohol- and drug-free living environment, peer support, and connection to recovery assistance for people with a substance use disorder who have completed treatment. Stella Maris operates a recovery community focused Coffee Shop that seats 45 and weekly 12 -Step support meet- 
ings. Upon completion of treatment, Stella Maris clients receive job readiness and placement services as well as recovery housing.

\section{Stella Maris’s responses to the pandemic}

During the recent recommendation for social distancing and physical separation related to the pandemic, the agency redesigned outpatient treatment using telehealth services. The web-hosted GoToMeeting service provided by the LogMeIn company was offered to Stella Maris for free for ninety days in response to the coronavirus crisis. The agency was able to ask over fifty percent of its staff to work remotely using GoToMeeting services and also offer individual and group therapy services to their clients who do not need to come physically to the agency. Stella Maris moved to pre-screen all clients over the phone for symptoms of COVID-19 in an effort to minimize potential infections arriving on campus. At this time, admissions to all levels of care continue, but the entryway for the housing units is only available through detox services in order to provide for greater screening capability. There are only twelve available beds - each of them in separate rooms to comply with social distancing requirements. Unfortunately, people looking for detox admission when all the beds are occupied cannot be admitted and are referred to the nearest hospitals. For Stella Maris, the pandemic crisis comes on top of the crises of opiate addiction and homelessness.

Stella Maris has twenty supportive housing beds to offer to the homeless and those beds typically are filled through referrals from a shelter for homeless men. These beds are still available, but there is a lack of medical staff and transport services that would be necessary if any resident became ill with COVID19 symptoms. However, Stella Maris continues to offer these housing services.

Usually, Stella Maris offers close to forty-five weekly 12-step meetings to their clients and the greater Cleveland community. The staff estimate that 1200-1500 non clients come to the Stella Maris campus each week to attend a support meeting. In the face of the pandemic, these meetings have all been put on hold. However, staff who are members of any twelve step program, plus longer term clients, have filled some of the gap with informal meetings daily. The community at large, as well as the staff, continue providing donations of food, clothing, games, and video games to make sure that clients will not experience idle time, which can be detrimental in early recovery. Daniel Lettenberger-Klein, the Executive Director of Stella Maris, remarked that both staff and clients have created a community working together in this difficult time, staying positive and appreciative of each other's good work.

The main ethical tensions that have arisen during these crisis responses are related to confidentiality and privacy concerns connected to telehealth. All members of staff have agreed to follow the strictest possible rules in relation to confidentiality. It is clear that the increasing public health demands require policies of transparency and new rules; these new policies and rules have been understood, accepted, and respected by all involved with Stella Maris. 
Background Description of Lutheran Metropolitan Ministry

Lutheran Metropolitan Ministry (LMM) is a 51-year-old Cleveland area nonprofit providing health \& wellness programs, housing \& shelter, and workforce development services. The cornerstone of LMM's housing \& shelter services is the Men's Shelter at 2100 Lakeside, the largest emergency shelter in Ohio serving 400 adult men per night and 3,400 annually. LMM is a member of the Cuyahoga County Continuum of Care (CoC), led by the Cleveland/Cuyahoga County Office of Homeless Services. As such, a great deal of systems coordination and partnership goes into the work at the Men's Shelter.

Many organizations partner with LMM to provide on-site medical care, housing and employment linkages, benefits enrollment, mental health case management, and other critical needs. Additionally, roughly 2,000 annual volunteers donate their time, resources, and/or services to shelter residents. Such ancillary services include legal clinics, digital literacy, recovery groups, and art workshops.

The shelter is divided into six dormitory-like communities, based on the resident's anticipated housing outcome (e.g. exiting to independent housing, Permanent Supportive Housing, etc.), with an average of 60 individuals per community. While the overall systems need has decreased since LMM began operating the shelter in 2005, typically there is not enough capacity at the Men's Shelter on a nightly basis. To meet this need, LMM operates an overflow facility in partnership with St. Pauls' Church to provide an additional 40 spaces for mats.

\section{LMM's responses to the pandemic}

The primary goal has been to increase physical separation among the homeless. This could be done only by increasing the shelter's physical space, which LMM has approached from several angles. One of the first acts implemented was attempting to divert as many residents as possible to live with family or friends. To incentivize this, LMM worked with the Office of Homeless Services to distribute gift cards to anyone who diverted, and to ensure that after the diversion they would not lose their reserved shelter placement or homeless status. This incentivizing act can be seen as an example of benign rationing of shelter space. However, this act may increase risks of infection or co-occuring consequences of adding a person to the family or friend household. For those who could not be diverted, LMM worked in partnership with the County's Office of Homeless Services, Cuyahoga County, and the City of Cleveland to secure emergency funding for moving residents to an 80-room hotel, with two men occupancy per room. Staff identified individuals staying in the Men's Shelter who were at increased risk for serious COVID19: those who are older or with a compromised immune system. LMM delivers the Men's Shelter's existing resources to the hotel in order to provide continuity of care and safety for residents. Social workers continue to meet face-toface with their clients and to maintain relationship. To date this has included on-site case management and facility operations during the day, overnight security monitoring, and technology synchronization so the Shelter's census can be updated daily to include hotel reservations. While shelter management has been working closely with 
the aforementioned partners, one of the greatest challenges has been and will likely continue to be maintaining appropriate staffing at multiple shelter/hotel sites, particularly as LMM anticipates that some staff will eventually become ill, perhaps as a result of continued service to clients.

Despite success in census reduction, much more work is needed to address the risks of the pandemic among people who are homeless. LMM and county leadership collaborate with neighboring organizations, colleges, and convents to secure additional spaces to house homeless individuals. It is estimated there are close 230 people looking for housing outside of the shelter. While these residents remain on-site at the Men's Shelter, staff have taken necessary precautions to protect their health and safety. This has included: ordering portable handwashing stations; increasing availability of cleaning products and personal protective equipment; suspending the volunteer program; creating a tracking system for symptom monitoring; providing remote work capacity for non-direct service staff; and maintaining frequent communication with staff, clients, and volunteers. LMM is also working with Cleveland Institute of Art design students to create a bed layout in the shelter that accommodates 6 -foot distance. This process will provide LMM with an accurate estimate of shelter beds that meet CDC spatial recommendations for homeless services providers, which will approximately only one third of the original capacity.

LMM's focus to date has been to address the residents' physical health and safety needs. As such, many important supportive services, which are provided by external partners and volunteers, have been cancelled. Many of LMM's partner community organizations have limited their community work. For those providers still interested in providing on-site services, they must evaluate if their potential to be a source of infection overrides the good that they may bring to the shelter. Ideally, tele-appointments could be coordinated for residents, but with the closure of the volunteer program, which includes a computer lab, there is limited computer access, and many residents do not have personal cell phones. Second, LMM's focus has been on working with medical providers to clearly identify workflow and systems coordination. The local MetroHealth hospital has been greatly supportive and provided critical guidance and direction for strategizing health care services for the most vulnerable population. Maintaining medical contacts has proven difficult as other health providers either work solely within their own organization or are quarantined due to potential contact with people who are infected. For most health care professionals and organizations, all elective appointments and services have been postponed for several months. Only those with urgent medical needs are seen. Third, as mentioned previously, long-term staffing is of concern. It has become clear that shelter staff working in the midst of a constant public crisis do not have much of a buffer as the crisis grows.

While much is still in flux, LMM has attempted to maintain the sense of community and support that is so essential to the mission. One example of this is that each day there is a message from a different volunteer to all in the shelter community. The message for March 27th was from a social work intern: "This unprecedented event has made me think of the concept of Ubuntu - I am because you are; my humanity is tied to yours. Wishing everyone peace”. 
In the examples of the two social service agencies described above, professionals from both Stella Maris and LMM clearly follow the same set of values as those earlier described for social work. The last example of the message to the entire LMM community illustrates the Value of Importance of Human Relationships.

The Coronavirus and COVID-19 pandemic is but several months old and has caused disruptions and hardship in every aspect of human life. Social workers and other health and human service professions are on the front lines of efforts to slow the virus's spread and to care for those in society who are most vulnerable to its effects. As a values driven profession, social work holds itself to high standards through the core values and principles. However, in time of crisis, these principles are only guidelines to how social workers and others must respond to the demands of critically ill people and shortages of needed medical and social resources. This paper presents only the beginning of the challenges for the care of vulnerable groups; we will face continuing problems of job loss, economic hardship, mental and physical strains among all levels of society after the threat of infection and illness has passed. The social work profession was tested and ultimately strengthened by the 1918 pandemic through efforts to communicate and to join together around common values and concerns. It is too soon to determine how the profession will be changed by the experiences of the COVID19 pandemic and how effective the current responses will prove to be. The values and ethical principles can set a path, but it will be the power of human relationships, innovation and dedication that will ultimately face the dilemmas and meet the needs.

\section{CONCLUSION}

Less than two months have passed since the Coronavirus and COVID-19 have been identified in the US, but the changes to daily life for all Americans have been extensive and unprecedented. This paper has barely touched the surface on the ways in which the profession of social work will respond over the coming months and years to the needs of the most vulnerable in society and to those societal changes that will create new and unexpected social challengers. The value of service and social workers' primary goal of helping people in need and addressing social problems is evident in many of the steps that cities and local community organizations have taken in response to COVID-19. The use of tele-health, either on-line or through the phone, has been used by many social service and housing agencies to maintain contact with clients. Telehealth options protect both workers and clients from exposure to the virus. While telehealth options have been available for a number of years, it can be expected that this method of service delivery will be more widely used and developed long after the dangers of this pandemic have passed. As mentioned, telehealth options fall short for clients without access to computers or to internet access, so advocacy efforts to address this digital divide can be expected to increase.

Social workers have responded to increased need through networks and collaborations with health care, social services and government/private organizations. For example, the immediate need additional shelter care space led to negotiations with the city government, with client's families and friends, with private sector hotels, 
with health care organizations and with local art students. As the crisis continues, additional cooperative efforts might be expected with software developers to locate and secure resources, to design effective applications for health educations and to monitor housing and service vacancies. Finally, the value of advocacy will continue to guide the social work response to issues of oppression and discrimination related to the pandemic. Advocacy efforts will be necessary to highlight emerging areas of inequality in medical care and social services. Once this pandemic has subsided, there will be many ways in which society will be changed - some for the better and some for the worse. The social work profession must continue to advocate for policies and programs that will meet emerging needs and will prepare society for the next natural disaster or pandemic that puts vulnerable lives at risk.

FUNDING: This research received no external funding.

CONFLICT OF INTEREST: The authors declare no conflict of interest.

ACKNOWLEDGEMENTS: Authors thank Daniel Lettenberger-Klein from Stella Maris and Erin Kray and Claire Billingsley from Lutheran Metropolitan Ministry for their contribution to this work.

\section{REFERENCES}

Aronson, Louise. 2020. “'Covid-19 kills only old people.' Only?” New York Times, March 22. Retrieved March 24, 2020 (https://www.nytimes.com/2020/03/22/opinion/ coronavirus-elderly.html).

Beddoe, Liz. 2020."Responding to a crisis: Social Work profession, policy, and practice.” Australian Social Work 73(2): 131-136. DOI: 10.1080/0312407X.2020.1720758

Bunis, Dena \& Jenny Rough. 2020. “Governors order Coronavirus-related restrictions across America.” AARP, March 27. Retrieved March 27, 2020 (https://www.aarp. org/politics-society/government-elections/info-2020/coronavirus-state-restrictions.html).

Cabanatuan, Michael. 2020. Coronavirus: Asian American groups compile hate crime reports as Trump persists in 'Chinese virus' attacks. San Francisco Chronicle, March 19. Retrieved March 28, 2020 (https://www.sfchronicle.com/bayarea/ article/Coronavirus-Asian-American-groups-compile-hate-15144295.php).

Code of ethics of the National Association of Social Workers. 2020. Washington, DC. NASW Press. Retrieved March 23, 2020 (https://www.socialworkers.org/ About/Ethics/Code-of-Ethics/Code-of-Ethics-English\%20\%20\%20\%20\%20\%20 \%20retrieved\%20on\%20March\%2023).

Farkas, Kathleen. 2020. Personal Communication. March 17, 2020.

Hutchins, Sonja S., Benedict I. Truman, Toby L. Merlin, \& Stephen C. Redd. 2009a. "Protecting vulnerable populations from pandemic influenza in the United States: A strategic imperative.” American Journal of Public Health 99(2): S243-S248. https:// 
doi.org/10.2105/AJPH.2009.164814

Hutchins, Sonja S., Kevin Fiscella, Robert S. Levine, Danielle C. Ompad, \& Marian McDonald. 2009b. "Protection of racial/ethnic minority populations during an influenza pandemic.” American journal of public health 99(2): S261-S270. https:// doi.org/10.2105/AJPH.2009.161505

Kerson, Toba S. 1979. "Sixty years ago: Hospital Social Work in 1918." Social Work in Health Care 4(3): 331-343. DOI: 10.1300/J010v04n03_08

Maglajlic, Reima A. 2019. "Organisation and delivery of social services in extreme events: Lessons from social work research on natural disasters.” International Social Work 62: 1146-1158. https://doi.org/10.1177/0020872818768387

Meng. 2020. "Meng Introduces resolution to denounce anti-Asian sentiment caused by coronavirus." March 25, 2020. Retrieved March 27, 2020 (https://raskin. house.gov/media/press-releases/meng-introduces-resolution-denounce-anti-asian-sentiment-caused-coronavirus).

Monnier, Jen. 2020. "Coronavirus Poses Unique Threat to U.S. Homeless Population.” Scientific American March 11. Retrieved March 25, 2020 (https://www.scientificamerican.com/article/coronavirus-poses-unique-threat-to-u-s-homeless-population1/).

Murphy, Mike. 2020. "Texas Lt. Gov. Dan Patrick says grandparents are willing to die to save economy for their grandkids." Market Watch March 23. Retrieved March 24, 2020 (https://www.marketwatch.com/story/texas-lt-gov-dan-patrick-says-grandparents-are-willing-to-die-to-save-economy-for-their-grandkids-2020-03-23).

Murphy, Tom. 2020. "Telemedicine emerges as care option during COVID19 outbreak." APNews March 21. Retrieved March 28, 2020 (https://apnews.com/54da28f75c478ac1130170677958a7b5).

NASW. 2020. "Message from NASW President Kathryn Conley Wehrmann regarding Coronavirus Covid-19 Pandemic.” Retrieved March 23, 2020 (https://www. socialworkers.org/News/News-Releases/ID/2110/Message-from-NASW-President-Kathryn-Conley-Wehrmann-regarding-Coronavirus-Covid-19-Pandemic).

Nemir, Samy. 2020. “LGBTQ advocacy groups sue Trump's HHS for refusing to enforce anti-discrimination rules, leaving community especially vulnerable amid COVID-19 pandemic." Lambda Legal March 19. Retrieved March 26, 2020 (https:// www.lambdalegal.org/news/ny_20200319 lgbtq-advocacy-groups-sue-hhs-refusing-to-enforce-anti-discrimination-rules-community-vulnerable-covid-19).

Ott, Miles, ShellyF.Shaw, RichardN.Danila, \& RuthLynfield.2007.“Lessonslearnedfrom the 1918-1919 influenza pandemic in Minneapolis and St. Paul, Minnesota." Public health reports 122(6): 803-810. https://doi.org/10.1177/003335490712200612

Partnership for Drug-Free Kids. 2020. "12-Step Programs Use Technology, Social Distancing During COVID19 Crisis.” March 19. Retrieved March 28, 2020 (https:// drugfree.org/learn/drug-and-alcohol-news/12-step-programs-use-technologysocial-distancing-during-covid-19-crisis/).

Ricciulli, Valeria. 2020. "How can New York City protect the homeless from coronavirus?” Curbed Newsletters March 13. Retrieved March 25, 2020 (https://ny.curbed. 
com/2020/3/13/21178079/coronavirus-nyc-homeless-services-covid-19).

Rosoff, Philip M. 2008. “The Ethics of Care: Social Workers in an Influenza Pandemic.” Social Work in Health Care 47(1): 49-59. DOI: 10.1080/00981380801970814

Schuetz, Jenny. 2020. “America's inequitable housing system is completely unprepared for coronavirus.” Brookings Institute March 12. Retrieved March 25, 2020 (https://www.brookings.edu/blog/the-avenue/2020/03/12/americas-inequitable-housing-system-is-completely-unprepared-for-coronavirus/).

Smith, Lauren A. 2020. "How to help the most vulnerable through the pandemic." The Chronicle of Philanthropy March 11. Retrieved March 25, 2020 (https://www. philanthropy.com/article/How-to-Help-the-Most/248227).

The Times Editorial Board. 2020. “How do we keep coronavirus from ravaging L.A.'s homeless encampments?” Los Angeles Time March 20. Retrieved March 25, 2020 (https://www.latimes.com/opinion/story/2020-03-20/editorial-how-to-prevent-coronavirus-from-ravaging-homeless-encampments).

World Health Organization. 2015. "Best Health Practices for the Naming of New Human Infectious Diseases. Retrieved March 28, 2020 (https://apps.who.int/iris/ bitstream/handle/10665/163636/WHO_HSE_FOS_15.1_eng.pdf?sequence=1).

\section{BIOGRAPHICAL NOTE}

Kathleen J. Farkas, Ph.D. LISW-Supv. is an Associate Professor of Social Work at the Jack, Joseph and Morton Mandel School of Applied Social Sciences, Case Western Reserve University, Cleveland, Ohio USA. She has extensive clinical and research experience in the areas of mental health and addictions assessment and treatment. Dr. Farkas a long time interest in substance use issues among older adults and women and her work has focused on addictions and mental health issues among those incarcerated in jails and prisons. Recently she has been involved in research, teaching and service efforts using animal assisted interventions in mental health and addictions. She is the chairperson of the Mandel School's direct practice faculty as well as the specialization faculty for substance use disorders and recovery.

J. Richard Romaniuk, PhD, LISW-S, LICDC, is a researcher and educator. Currently he works as a fulltime lecturer at the Mandel School of Applied Social Sciences. From 2004 to 2015 he worked as a social worker at the Louis Stokes Cleveland Department of Veterans Affairs Medical Center. He also worked in the School of Medicine, Case Western Reserve University as a neuroscientist. His experience at the VA has led him to participate in national VA committees and the National Association of Social Workers in Ohio. He was also involved locally, as a Board member of The Alcohol, Drug Addiction and Mental Health Services (ADAMHS) Board of Cuyahoga County (2010-2017).

OPEN ACCESS: This article is distributed under the terms of the Creative Commons Attribution Non-commercial License (CC BY-NC 4.0) which permits any non-commercial use, and reproduction in any medium, provided the original author(s) and source are credited.

ARTICLE HISTORY: Received 2020-03-30 / Accepted 2020-04-06 